\title{
Systematic Review and Meta-analysis of Circulating Fetuin-A Levels in Nonalcoholic Fatty Liver Disease
}

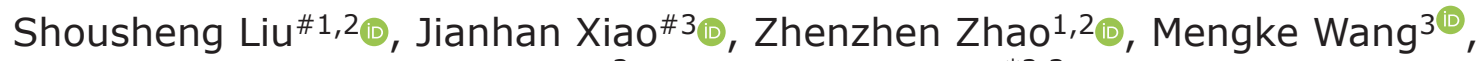 \\ Yifen Wang ${ }^{3}$ al and Yongning Xin*2,3
}

\begin{abstract}
${ }^{1}$ Clinical Research Center, Qingdao Municipal Hospital, Qingdao University, Qingdao, Shandong, China; ${ }^{2}$ Digestive Disease Key Laboratory of Qingdao, Qingdao, Shandong, China; ${ }^{3}$ Department of Infectious Disease, Qingdao Municipal Hospital, Qingdao University, Qingdao, Shandong, China; "These two authors contributed equally to this work.
\end{abstract}

\begin{abstract}
Background and Aims: Accumulated studies have reported the key role of circulating fetuin-A in the development and progression of nonalcoholic fatty liver disease (NAFLD) but the results have not been consistent. In this study, we performed a systematic review and meta-analysis to explore the relationship between circulating fetuin-A level and the development and classification of NAFLD. Methods: The PubMed, EMBASE, and Cochrane Library databases were searched to obtain the potentially relevant studies up to May 2020. Standardized mean differences (SMD) and $95 \%$ confidence intervals of circulating fetuin-A levels were extracted and summarized. Sensitivity, subgroup analysis and meta-regression analysis were performed to investigate the potential heterogeneity. Association of circulating fetuin-A level with classification of NAFLD was also reviewed. Results: A total of 17 studies were included, composed of 1,755 NAFLD patients and 2,010 healthy controls. Metaanalysis results showed that NAFLD patients had higher circulating fetuin-A level (SMD $=0.43,95 \%$ confidence interval $[C I]: 0.22-0.63, p<0.001$ ) than controls. Subgroup analysis indicated that circulating fetuin-A level was markedly increased in adult NAFLD patients $(\mathrm{SMD}=0.48,95 \%$ CI: $0.24-0.72, p<0.001)$ and not in pediatric/adolescent patients compared to controls. Circulating fetuin-A level was markedly increased in ultrasound-proven NAFLD pediatric/adolescent patients (SMD $=0.42,95 \% \mathrm{CI}: 0.12-0.72$, $p=0.007)$, other than in the liver biopsy-proven NAFLD pediatric/adolescent patients. Body mass index might be the influencing factor to the heterogeneity in adult patients. Circulating fetuin-A level was not associated with the classification of NAFL vs. nonalcoholic steatohepatitis (NASH). Whether the circulating fetuin-A level was associated with the development of fibrosis remains controversial. Conclusions: Circulating fetuin-A level was significantly higher in NAFLD patients and was not associated with the classification of NAFL vs. NASH. Whether the circulating fetuin-A level was associated with the development of fibrosis remains controversial.
\end{abstract}

Keywords: Nonalcoholic fatty liver disease; Fetuin-A; Meta-analysis; Fibrosis. Abbreviations: ARHQ, Agency for Healthcare Research and Quality; BMI, body mass index; CI, confidence interval; $\mathrm{HCC}$, hepatocellular carcinoma; NAFL, nonalcoholic fatty liver; NAFLD, nonalcoholic fatty liver disease; NASH, nonalcoholic steatohepatitis; NOS, Newcastle-Ottawa scale; SD, standard deviation; SMD, standardized mean differences.

Received: 25 August 2020; Revised: 12 October 2020; Accepted: 07 November 2020

*Correspondence to: Yongning Xin, Department of Infectious Disease, Qingdao +86-532-82789463, Fax: +86-532-85968434, E-mail: xinyongning@163.com
Citation of this article: Liu S, Xiao J, Zhao Z, Wang M, Wang $Y$, Xin $Y$. Systematic review and meta-analysis of circulating fetuin-A levels in nonalcoholic fatty liver disease. J Clin Transl Hepatol 2021;000(000):000-000. doi: 10.14218/JCTH.2020.00081.

\section{Introduction}

Nonalcoholic fatty liver disease (NAFLD) has become one of the most common chronic liver diseases in recent years, and the overall prevalence of NAFLD is approximately $25 \%$ in the world. 1,2 There is a broad spectrum of NAFLD, which ranges from nonalcoholic fatty liver (NAFL) to nonalcoholic steatohepatitis (NASH), fibrosis, cirrhosis, and even hepatocellular carcinoma (HCC).3,4 NAFLD is the hepatic manifestation of metabolic syndrome and is affected by many risk factors, such as obesity, hyperglycemia, type 2 diabetes, and hypertriglyceridemia usually. ${ }^{5}$ However, under certain conditions, mostly during genetically-determined NAFLD (such as in carriers of the TM6SF2 E167K or PNPLA3 I148M gene polymorphism), NAFLD does not show association with the metabolic syndrome and an increased risk of cardiovascular disease. ${ }^{6}$

Liver biopsy remains the gold standard for diagnosis and histological assessment of NAFLD, but the obvious defects (e.g., invasiveness, inter-observer differences, sampling error) cannot be ignored.7,8 In clinical practice, imaging methods such as ultrasonography, computed tomography, controlled attenuation parameter and magnetic resonance have been used widely for diagnosing NAFLD. ${ }^{9-13}$ In addition, many studies have been conducted to explore the valuable serum biomarkers for early diagnosis and progression of NAFLD. Several serum biomarkers, such as alanine aminotransferase, aspartate aminotransferase, gamma-glutamyltranspeptidase, cytokeratin-18 and fibroblast growth factor 21 , have been researched in some studies and their potential to serve as the biomarkers in clinical diagnosing of NAFLD have been mentioned. ${ }^{14-18}$

Fetuin-A, also known as the 2-Heremans-Schmid glycoprotein, is a phosphorylated glycoprotein and a member of the fetuin group of serum binding proteins that are synthesized primarily by hepatocytes. ${ }^{19}$ As an endogenous inhibitor of tyrosine kinase, fetuin-A can trigger insulin resistance in the target tissues, such as liver and skeletal muscle.20,21 Pal et al. ${ }^{22}$ reported that fetuin-A acts as an endogenous ligand for toll-like receptor 4 and could enhance both insulin resistance and inflammation response. High serum fetuinA was also found to strongly interact with the high levels of free fatty acids to induce insulin resistance in rodents, 
Liu S. et al: Circulating fetuin-A levels in NAFLD

which was then observed in large human studies; moreover, the relationships of fetuin-A with fatty acids, to determine insulin resistance, were particularly strong in patients with NAFLD. 23,24 Fetuin-A is also known to inhibit transforming growth factor-b1 signaling, which promotes fibrotic changes in many tissues, including liver and arteries; therefore, fetuin-A could prevent fibrotic changes in organs. ${ }^{25,26} \mathrm{Re}-$ cently, fetuin-A has been regarded as a potential link molecule between obesity, insulin resistance, and coronary heart disease, ${ }^{27-31}$ and was found to be strongly related to several parameters such as circulating lipid levels (non-esterified free fatty acids and triglycerides), glucose tolerance, circulating pro-inflammatory and anti-inflammatory factors, and interleukin-6. ${ }^{32}$ Fetuin-A can also induce low-grade inflammation and repress adiponectin production in animals and humans, playing an important role in the pathogenesis of insulin and possessing a pro-adiposity effect. ${ }^{33,34}$ Accumulated lines of evidence have reported the significant association between circulating fetuin-A level and the development and progression of NAFLD, but the results have been inconsistent. Additionally, there has been no definite conclusion as to whether circulating fetuin-A can reflect the grading of NAFL $v s$. NASH and advanced fibrosis.

The aim of this study was to investigate the importance of fetuin-A in the development and classification of NAFLD.

\section{Methods}

\section{Search strategy}

This systematic review and meta-analysis was conducted following a priori established protocol and was reported according to PRISMA guidelines. ${ }^{35}$ Two independent observers (Shousheng Liu and Jianhan Xiao) performed a systematic search of the PubMed, EMBASE, and the Cochrane Library databases up to May 2020 and with English language restrictions. The first step for information retrieval was to gain the subject term of fetuin-A, NAFLD or NASH in the MeSH database of PubMed; meanwhile, we gained the entry terms of them, respectively. The combined results of fetuin- $A$, NAFLD or NASH in the three databases were obtained based on the search method of "subject term + entry terms". In addition, we examined the reference lists in relevant original research and review articles to search additional potentially eligible studies.

\section{Inclusion and exclusion criteria}

Studies that investigated the circulating fetuin-A level in patients with NAFLD were eligible for review. Studies were included in this systematic review and meta-analysis if they met the following criteria: (1) original full-text publications; (2) comparison of circulating fetuin-A level between NAFLD patients and healthy controls; (3) investigations of the effect of circulating fetuin-A level on the classification of NAFL vs. NASH or fibrosis. Studies were excluded according to the following criteria: (1) patients with other causes of liver disease (e.g., viral or autoimmune hepatitis, alcoholic fatty liver disease, HCC, coronary artery disease) or in whom NAFLD co-existed with another liver disease; $(2)$ there was overlap of patients who were included in more than one study. Quality of case-control studies were evaluated use the Newcastle-Ottawa scale (NOS) scoring system and the quality of cross-sectional studies were evaluated use the Agency for Healthcare Research and Quality (ARHQ) scoring system. ${ }^{36}$ (3) Studies of low methodological quality, as defined by a NOS score $\leq 2$ or ARHQ score $\leq 3$, were exclud- ed. Finally, (4) reviews, editorials, case reports, conference abstracts, letters to the editor, hypotheses, book chapters, and studies on animals or cell lines were excluded.

\section{Data extraction}

Available data were extracted from the full text and corresponding supplemental information by two investigators working independently (Shousheng Liu and Jianhan Xiao) and confirmed by a third reviewer (Zhenzhen Zhao). Disagreement was resolved by discussion among all researchers. The following information of each selected publication was extracted: (1) general characteristics, such as first author's name, year of publication, country where the study was carried out, study design, diagnostic methods of NAFLD, type of samples (e.g., serum, plasma, blood); (2) subjects' characteristics, such as age, gender, body mass index (BMI); and (3) effect of circulating fetuin-A on the grading of NAFL $v s$. NASH or fibrosis. When the same population was published in several journals, we retained only the most informative article or complete study, to avoid duplication. If some necessary data were not offered in the article, the corresponding author would be contacted for the data. If no response, the following methods would be carried out: (1) data from the graphical plots were extracted to calculate the circulating fetuin-A levels by using WebPlotDigitizer (version 4.1.0, https://apps.automeris.io/wpd/); ${ }^{37}$ (2) circulating fetuin-A levels which were expressed as median (mixmix) or median (25-75 quartile) were transformed into the standard form of mean, according to the Cochrane book or method (Hozo, Stela Pudar et al. ${ }^{38}$ ).

\section{Quality assessment}

The included studies in the systematic review and metaanalysis were independently assessed by two investigators (Shousheng Liu and Jianhan Xiao). We assessed the quality of included case-control studies based on the NOS scoring system, and cross-sectional studies based on the AHRQ scoring system. The full NOS score was 9 stars; a study that met 7 or more stars was defined as a high-quality study, less than 3 stars as low-quality and other studies were defined as moderate quality. Article quality by AHRQ was assessed as follows: low quality: 0-3; moderate quality: 4-7; and high quality: 8-11.

\section{Statistical analysis}

All statistical analyses were performed using Stata12.0 (StataCorp LP, College Station, TX, USA). The effect sizes were generated by sample sizes, mean circulating fetuinA levels, and the standard deviation (SD), and presented as standardized mean differences (SMD) and 95\% confidence intervals ( $95 \%$ CIs) for circulating fetuin-A levels in comparisons between groups. Given the expected heterogeneity of the outcome, a random-effect inverse-variance model was chosen for this meta-analysis. 39 The heterogeneity between the results of different studies was evaluated using the $I^{2}$ statistic, values of $I^{2}>50 \%$ were considered to represent substantial heterogeneity. The potential moderating effects of continuous variables on between-study heterogeneity were evaluated by meta-regression analyses and subgroup-analysis. Subgroup-analysis were first conducted according to age, region, and diagnostic method of NAFLD, then the sex distribution (number of males), mean age, BMI and HOMA-IR of NAFLD patients were regarded as the potential moderators for the adult outcome of the 
Liu S. et al: Circulating fetuin-A levels in NAFLD
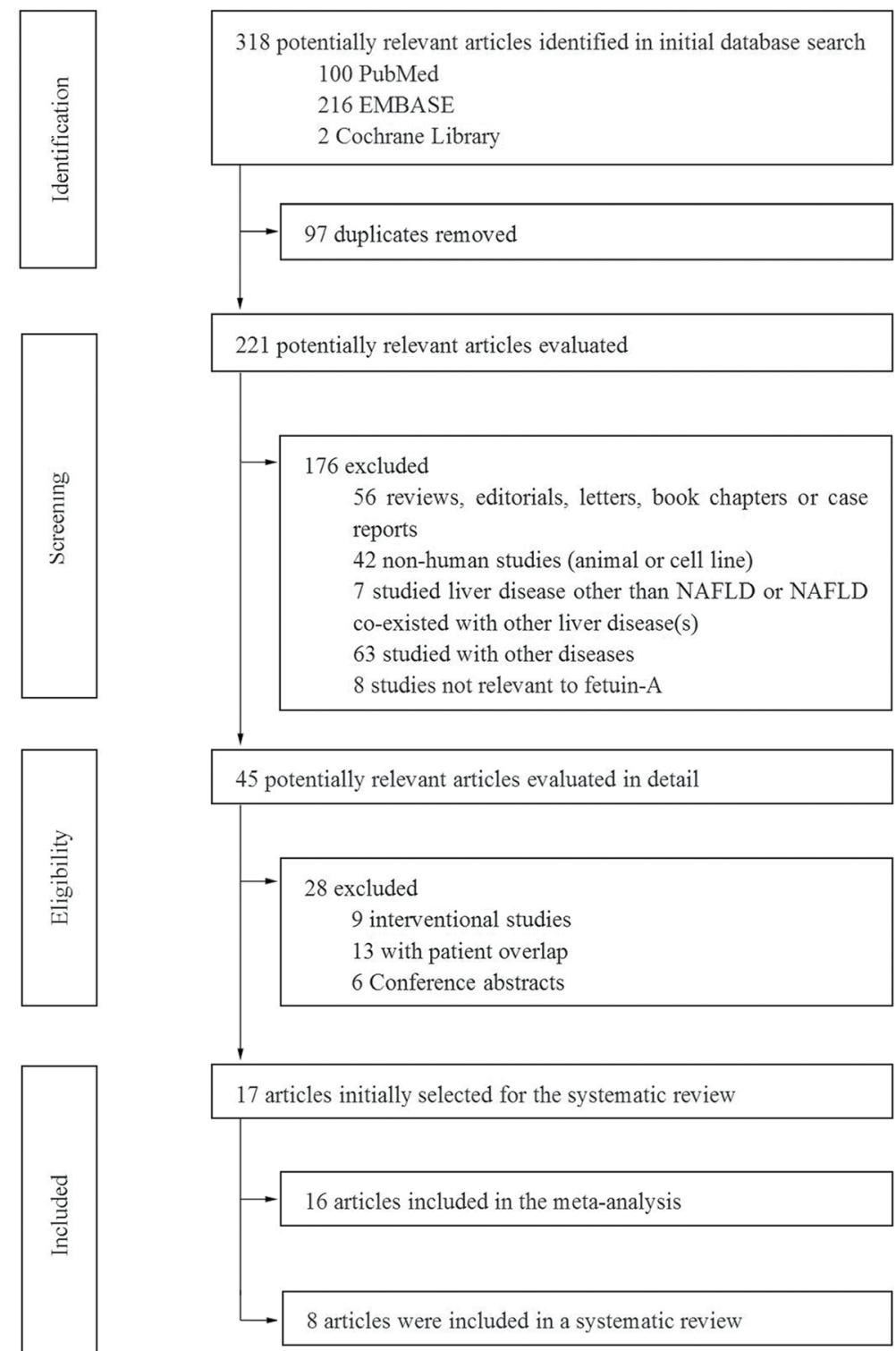

Fig. 1. Flowchart presenting the literature search process, according to the PRISMA statement.

meta-analysis when a high heterogeneity of adult NAFLD was observed. Sensitivity analysis was performed to investigate the influence of each study on the pooled measures by omitting a study each time to assess the stability of our results. A $p$-value of $<0.05$ was considered to indicate a statistical difference. Publication bias was assessed by funnel plot and Begg's and Egger's tests.

\section{Results}

\section{Literature search}

A total of 318 studies were retrieved initially from the three databases. After removing duplications $(n=97), 221$ studies remained for evaluation. In all, 204 studies were excluded for representing reviews, editorials, letters, book chapters or case reports, animal or cell experiments, other liver diseases, patient overlap, conference abstracts, and so on (Fig. 1). The final dataset for the systematic review and meta-analysis comprised 17 full-text studies. 25,27,28,40-53 Among them, 16 studies were selected to conduct the meta-analysis and 8 studies were selected to investigate the relationship between circulating fetuin-A level and the classification of NAFL $v s$. NASH.

\section{Characteristics of included studies}

A total of 1,755 NAFLD patients and 2,010 healthy controls were included in the 17 studies, the main characteristics of these studies are shown in Table 1 . Among these studies, two were conducted with the same participants, but the former investigated the association of plasma fetuin-A level with NAFLD; 44 however, the latter study not only investi- 
Liu S. et al: Circulating fetuin-A levels in NAFLD

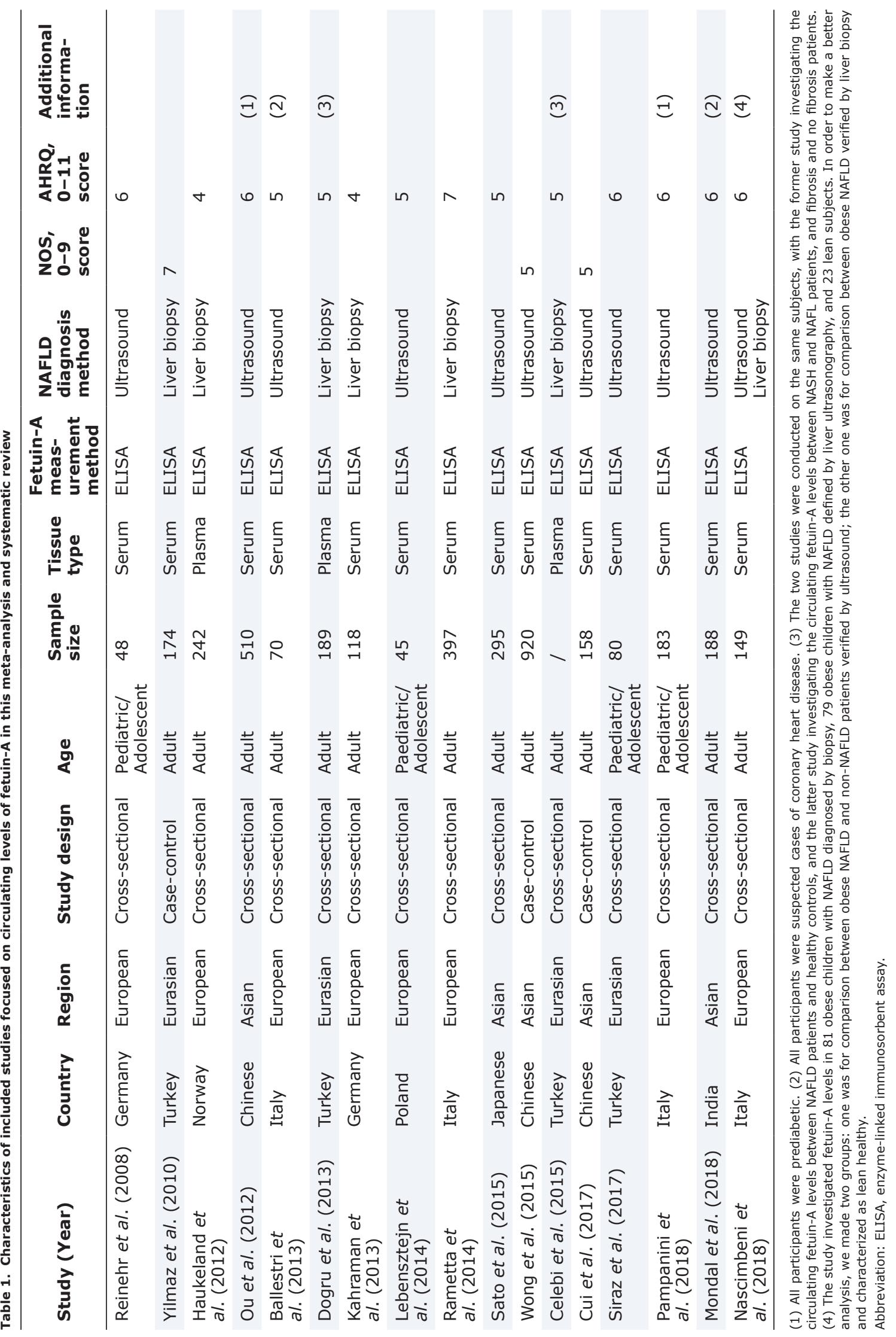


gated the relationship between plasma fetuin-A level and NASH or NAFL but also investigated the association of plasma fetuin-A level and fibrosis. ${ }^{47}$ As such, 16 studies were selected to perform the meta-analysis.

Studies in this meta-analysis included three case-control and thirteen cross-sectional designs. Enzyme-linked immunosorbent assay was used to test the serum/plasma fetuin-A level in all the studies. Liver biopsy was performed to determine the NAFLD in six studies, and ultrasound was used in other ten. Another study, conducted by Pampanin et al. $^{2}, 27$ diagnosed NAFLD with both liver biopsy and ultrasound in different groups; so, we regarded this study as two individual studies. Among these studies, six performed the comparison of circulating fetuin-A level between NAFL and NASH patients and eight determined the relationship of circulating fetuin-A level with liver fibrosis (Table 2).

\section{Quality of included studies}

The qualities of included case-control or cohort studies were assessed based on the NOS, and the cross-sectional studies were assessed based on the ARHQ methodology checklist. ${ }^{36}$ The detailed quality scores of each study are shown in Table 1 . All the studies were assessed as moderate quality. No study was eliminated due to low quality (NOS score $\leq 2$ or AHRQ score $\leq 3$ ).

\section{Effect of circulating fetuin-A level on NAFLD}

A random-effect meta-analysis was performed to investigate the effect of circulating fetuin-A level on the development of NAFLD. As the results show in Fig. 2A, the circulating fetuin-A level in NAFLD patients was significantly higher than in healthy controls, with a summarized SMD of 0.43 (95\%CI: $0.22-0.63, p<0.001)$. A striking heterogeneity among included studies was observed in the comparison of circulating fetuin-A level in NAFLD patients and healthy controls; the $I^{2}$ value was $85.7 \%(p<0.001)$.

Subgroup analysis based on age implied that the circulating fetuin-A level of NAFLD patients was significantly elevated in adults (SMD $=0.48,95 \% \mathrm{CI}: 0.24-0.72, p<0.001)$ and no obvious difference was observed in pediatric/adolescent patients (SMD $=0.25,95 \% \mathrm{CI}:-0.18-0.67, p=0.256)$ (Fig. $2 \mathrm{~B}$ ). Based on age, we also performed subgroup analysis according to the region of subjects and diagnostic method of NAFLD, respectively. As shown in Fig. $3 A$, the circulating fetuin-A level in adult NAFLD patients was increased among Europeans (SMD $=0.71,95 \% \mathrm{CI}: 0.35-1.07, p<0.001)$, and no significant differences were observed in the Eurasians $(\mathrm{SMD}=0.73,95 \% \mathrm{CI}:-0.04-1.50, p=0.062)$ nor Asians $(\mathrm{SMD}=0.18,95 \% \mathrm{CI}:-0.08-0.43, p=0.174)$. In the pediatric/adolescent group, there was no significant difference of circulating fetuin-A level between NAFLD patients and controls of European populations (SMD $=0.27,95 \% \mathrm{CI}:-0.25-$ $0.79, p=0.303)$ and Eurasian populations $(S M D=0.15,95 \%$ CI: $-0.58-0.88, p=0.688)$. Subgroup analysis results according to NAFLD diagnosis method (ultrasound $v s$. liver biopsy) are shown in Fig. 3B. In adults, the level of circulating fetuin-A was higher in both ultrasound-proven NAFLD patients and liver biopsy-proven NAFLD patients than in healthy controls (SMD $=0.21,95 \% \mathrm{CI}: 0.01-0.42$, $p<0.001$; SMD $=0.86,95 \% \mathrm{CI}: 0.51-1.21, p<0.001$, respectively). Interestingly, the circulating fetuin-A level in ultrasound-proven NAFLD pediatric/adolescent patients was significantly increased compared to pediatric/adolescent controls (SMD $=0.42,95 \% \mathrm{CI}: 0.12-0.72, p=0.007)$, but no difference was observed between the liver biopsyproven NAFLD pediatric/adolescent patients and healthy

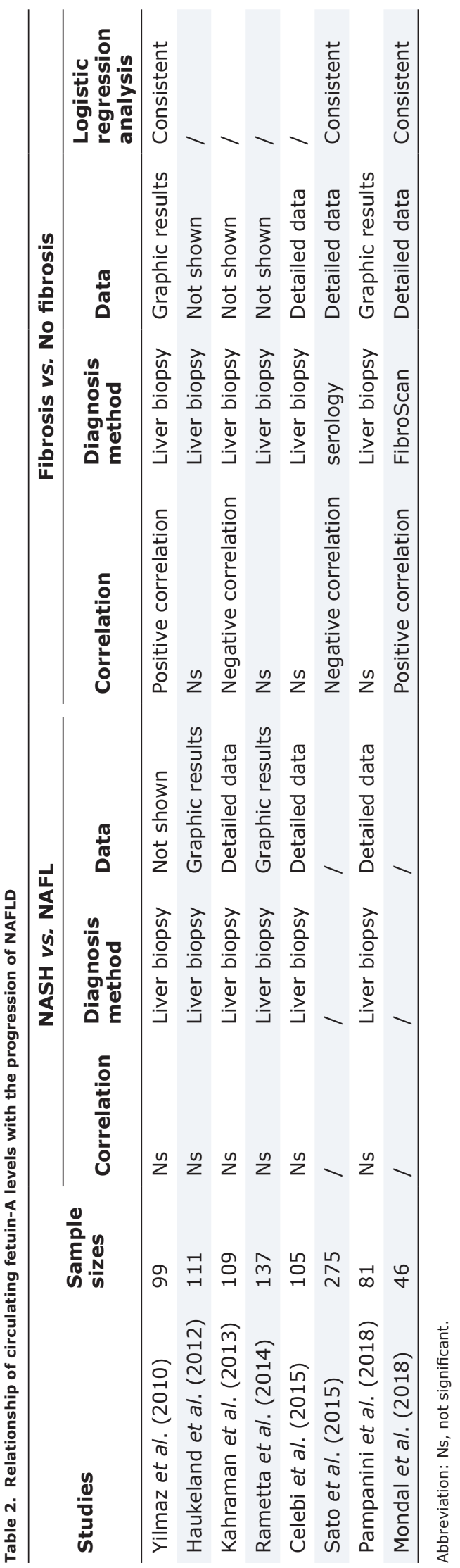


Liu S. et al: Circulating fetuin-A levels in NAFLD

A

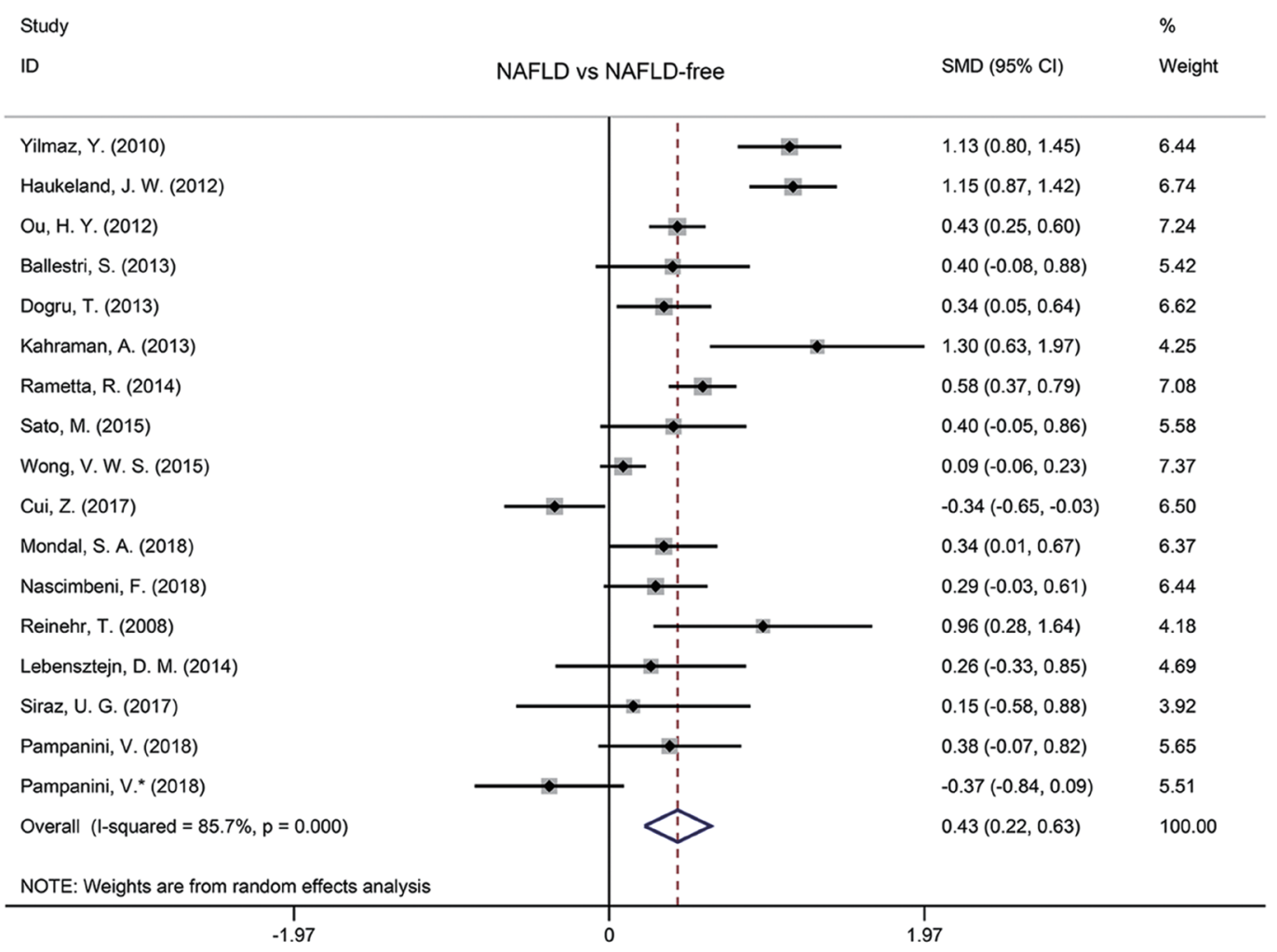

B

Study
ID

Fig. 2. Meta-analysis and influence of age. (A) Meta-analysis of the circulating fetuin-A levels in the included NAFLD patients compared to healthy controls. (B) Subgroup analysis on the difference of circulating fetuin-A levels between the included NAFLD patients and healthy controls based on age. 
Liu S. et al: Circulating fetuin-A levels in NAFLD

A

\begin{tabular}{|c|c|c|c|}
\hline $\begin{array}{l}\text { Study } \\
\text { ID }\end{array}$ & Subgroup-analysis on Region & SMD $(95 \% \mathrm{Cl})$ & $\begin{array}{l}\% \\
\text { Weight }\end{array}$ \\
\hline adultEurasian & & & \\
\hline Yilmaz, Y. (2010) & $\longrightarrow$ & $1.13(0.80,1.45)$ & 6.44 \\
\hline Dogru, T. (2013) & $\frac{1}{1}$ & $0.34(0.05,0.64)$ & 6.62 \\
\hline Subtotal $(I-$ squared $=91.9 \%, p=0.000)$ & & $0.73(-0.04,1.50)$ & 13.06 \\
\hline adultEuropean & & & \\
\hline Haukeland, J. W. (2012) & $\longrightarrow$ & $1.15(0.87,1.42)$ & 6.74 \\
\hline Ballestri, S. (2013) & & $0.40(-0.08,0.88)$ & 5.42 \\
\hline Kahraman, A. (2013) & & $1.30(0.63,1.97)$ & 4.25 \\
\hline Rametta, R. (2014) & & $0.58(0.37,0.79)$ & 7.08 \\
\hline Nascimbeni, F. (2018) & 1 & $0.29(-0.03,0.61)$ & 6.44 \\
\hline Subtotal $(1-$ squared $=82.0 \%, p=0.000)$ & & $0.71(0.35,1.07)$ & 29.93 \\
\hline . & & & \\
\hline adultAsian & & & \\
\hline Ou, H. Y. (2012) & & $0.43(0.25,0.60)$ & 7.24 \\
\hline Sato, M. (2015) & & $0.40(-0.05,0.86)$ & 5.58 \\
\hline Wong, V. W. S. (2015) & i & $0.09(-0.06,0.23)$ & 7.37 \\
\hline Cui, Z. (2017) & $\rightarrow$ & $-0.34(-0.65,-0.03)$ & 6.50 \\
\hline Mondal, S. A. (2018) & & $0.34(0.01,0.67)$ & 6.37 \\
\hline Subtotal (I-squared $=81.3 \%, p=0.000$ ) & & $0.18(-0.08,0.43)$ & 33.06 \\
\hline . & & & \\
\hline paediatric/adolescentEuropean & ! & & \\
\hline Reinehr, T. (2008) & & $0.96(0.28,1.64)$ & 4.18 \\
\hline Lebensztejn, D. M. (2014) & & $0.26(-0.33,0.85)$ & 4.69 \\
\hline Pampanini, V. (2018) & & $0.38(-0.07,0.82)$ & 5.65 \\
\hline Pampanini, V.* (2018) & 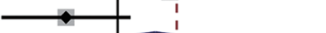 & $-0.37(-0.84,0.09)$ & 5.51 \\
\hline Subtotal $($ I-squared $=73.3 \%, p=0.011)$ & & $0.27(-0.25,0.79)$ & 20.03 \\
\hline paediatric/adolescentEurasian & & & \\
\hline Siraz, U. G. (2017) & & $0.15(-0.58,0.88)$ & 3.92 \\
\hline Subtotal $(\mathrm{I}-$ squared $=. \%, \mathrm{p}=$. ) & 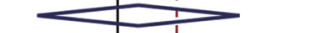 & $0.15(-0.58,0.88)$ & 3.92 \\
\hline Overall $(I-$ squared $=85.7 \%, p=0.000)$ & & $0.43(0.22,0.63)$ & 100.00 \\
\hline \multicolumn{4}{|c|}{ NOTE: Weights are from random effects analysis } \\
\hline $\begin{array}{c}1 \\
-1.97 \\
\end{array}$ & 0 & & \\
\hline
\end{tabular}

B

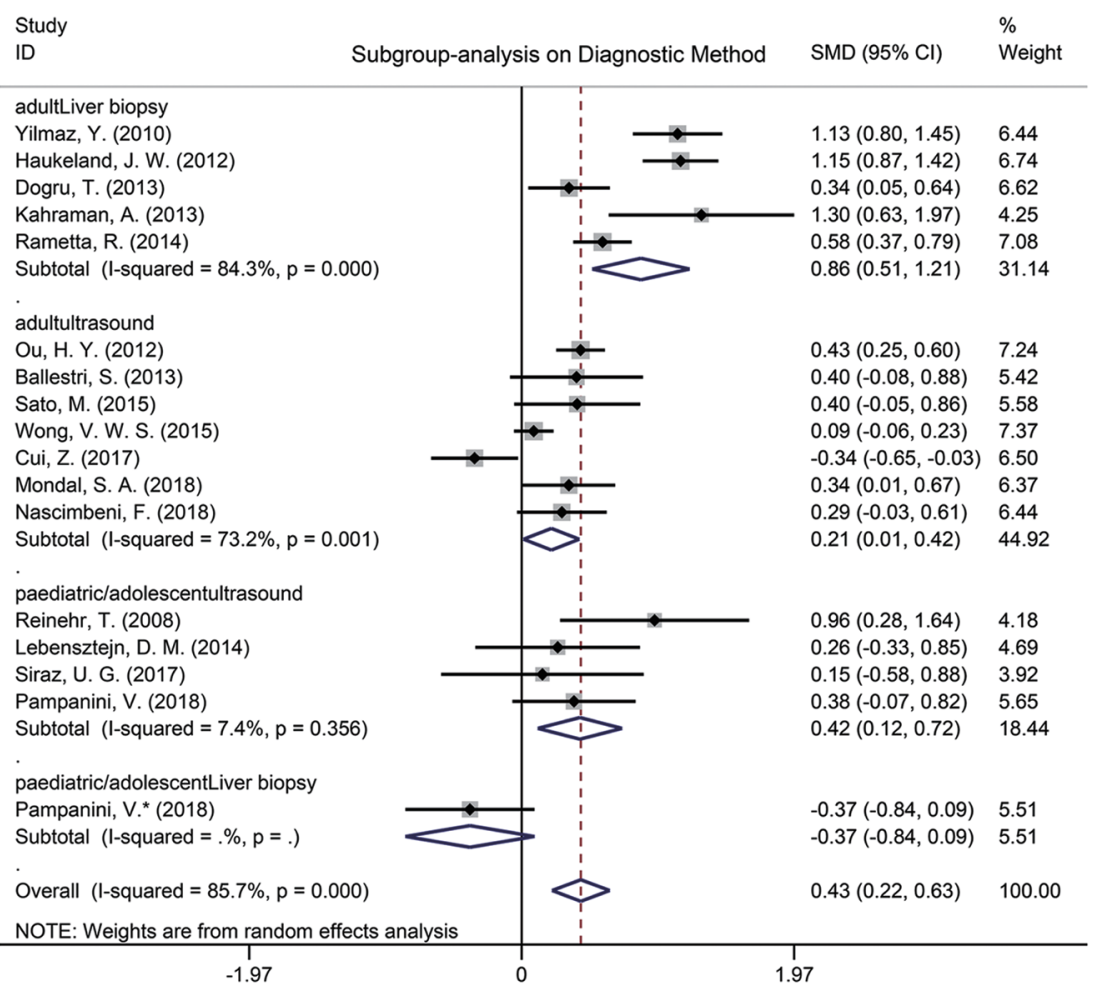

Fig. 3. Influence of region and diagnostic method. (A) Subgroup analysis on the difference of circulating fetuin-A levels between the included NAFLD patients and healthy controls based on region. (B) Subgroup analysis on the difference of circulating fetuin-A levels between the included NAFLD patients and healthy controls based on diagnostic method. 
Liu S. et al: Circulating fetuin-A levels in NAFLD

Table 3. Demographic and clinical data of patients with NAFLD and healthy controls among the adults

\begin{tabular}{|c|c|c|c|c|c|c|}
\hline Studies & Group & Size, $n$ & Males, \% & $\begin{array}{l}\text { Age in years, } \\
\text { mean (SD) }\end{array}$ & $\begin{array}{l}\text { BMI in } \mathbf{k g} / \mathbf{m}^{2}, \\
\text { mean (SD) }\end{array}$ & HOMA-IR \\
\hline Yilmaz et al. (2010) & $\begin{array}{l}\text { NAFLD } \\
\text { Control }\end{array}$ & $\begin{array}{l}99 \\
75\end{array}$ & $\begin{array}{l}46.0 \\
51.0\end{array}$ & $\begin{array}{l}47.0(9.0) \\
47.0(8.0)\end{array}$ & $\begin{array}{l}30.7(4.9) \\
27.5(4.3)\end{array}$ & $\begin{array}{l}3.80(0.40) \\
1.40(0.30)\end{array}$ \\
\hline Haukeland et al. (2012) & $\begin{array}{l}\text { NAFLD } \\
\text { Control }\end{array}$ & $\begin{array}{l}111 \\
131\end{array}$ & $\begin{array}{l}60.0 \\
44.0\end{array}$ & $\begin{array}{l}46.5(11.6) \\
43.3(3.0)\end{array}$ & $\begin{array}{l}30.5(4.3) \\
23.9(3.0)\end{array}$ & $\begin{array}{l}2.21(1.14) \\
1.40(0.77)\end{array}$ \\
\hline Ou et al. (2012) & $\begin{array}{l}\text { NAFLD } \\
\text { Control }\end{array}$ & $\begin{array}{l}255 \\
255\end{array}$ & $\begin{array}{l}56.0 \\
60.0\end{array}$ & $\begin{array}{l}61.1(10.3) \\
62.1(11.3)\end{array}$ & $\begin{array}{l}26.7(3.1) \\
23.3(2.8)\end{array}$ & $\begin{array}{l}1.21(0.12) \\
0.58(0.16)\end{array}$ \\
\hline Ballestri et al. (2013) & $\begin{array}{l}\text { NAFLD } \\
\text { Control }\end{array}$ & $\begin{array}{l}29 \\
41\end{array}$ & $\begin{array}{l}69.0 \\
68.3\end{array}$ & $\begin{array}{l}64.5(10.5) \\
70.6(12.7)\end{array}$ & $\begin{array}{l}29.2(5.0) \\
25.8(3.1)\end{array}$ & $\begin{array}{l}1.50(0.325) \\
1.40(0.350)\end{array}$ \\
\hline Dogru et al. (2013) & $\begin{array}{l}\text { NAFLD } \\
\text { Control }\end{array}$ & $\begin{array}{l}115 \\
74\end{array}$ & $\begin{array}{l}100.0 \\
100.0\end{array}$ & $\begin{array}{l}31.0(5.2) \\
28.0(5.2)\end{array}$ & $\begin{array}{l}28.4(2.97) \\
24.0(2.65)\end{array}$ & $\begin{array}{l}3.35(2.18) \\
1.22(0.62)\end{array}$ \\
\hline Kahraman et al. (2013) & $\begin{array}{l}\text { NAFLD } \\
\text { Control }\end{array}$ & $\begin{array}{l}108 \\
10\end{array}$ & $\begin{array}{l}23.0 \\
50.0\end{array}$ & $\begin{array}{l}41.9(0.9) \\
32.5(5.5)\end{array}$ & $\begin{array}{l}53.3(1.1) \\
23.9(1.2)\end{array}$ & $\begin{array}{l}\mathrm{Na} \\
\mathrm{Na}\end{array}$ \\
\hline Rametta et al. (2014) & $\begin{array}{l}\text { NAFLD } \\
\text { Control }\end{array}$ & $\begin{array}{l}137 \\
260\end{array}$ & $\begin{array}{l}77.4 \\
80.0\end{array}$ & $\begin{array}{l}49.7(12.1) \\
47.7(12.1)\end{array}$ & $\begin{array}{l}26.9(3.4) \\
25.1(2.8)\end{array}$ & $\begin{array}{l}2.50(2.80) \\
1.30(0.20)\end{array}$ \\
\hline Sato et al. (2015) & $\begin{array}{l}\text { NAFLD } \\
\text { Control }\end{array}$ & $\begin{array}{l}275 \\
20\end{array}$ & $\begin{array}{l}55.0 \\
65.0\end{array}$ & $\begin{array}{l}56.4(6.9) \\
61.0(7.0)\end{array}$ & $\begin{array}{l}26.5(3.6) \\
22.2(2.6)\end{array}$ & $\begin{array}{l}\mathrm{Na} \\
\mathrm{Na}\end{array}$ \\
\hline Wong et al. (2015) & $\begin{array}{l}\text { NAFLD } \\
\text { Control }\end{array}$ & $\begin{array}{l}263 \\
657\end{array}$ & $\begin{array}{l}54.0 \\
37.4\end{array}$ & $\begin{array}{l}51.0(9.0) \\
47.0(11.0)\end{array}$ & $\begin{array}{l}25.3(4.0) \\
21.3(3.1)\end{array}$ & $\begin{array}{l}2.50(0.37) \\
1.10(0.15)\end{array}$ \\
\hline Cui, Xuan, and Yang (2017) & $\begin{array}{l}\text { NAFLD } \\
\text { Control }\end{array}$ & $\begin{array}{l}79 \\
79\end{array}$ & $\begin{array}{l}73.0 \\
73.0\end{array}$ & $\begin{array}{l}42.0(10.8) \\
40.0(12.0)\end{array}$ & $\begin{array}{l}26.0(3.0) \\
22.0(2.0)\end{array}$ & $\begin{array}{l}3.27(2.18) \\
1.81(1.80)\end{array}$ \\
\hline Mondal et al. (2018) & $\begin{array}{l}\text { NAFLD } \\
\text { Control }\end{array}$ & $\begin{array}{l}46 \\
142\end{array}$ & $\begin{array}{l}57.0 \\
66.0\end{array}$ & $\begin{array}{l}49.5(12.2) \\
46.2(12.7)\end{array}$ & $\begin{array}{l}27.5(6.2) \\
25.7(4.8)\end{array}$ & $\begin{array}{l}1.10(0.26) \\
1.10(0.10)\end{array}$ \\
\hline Nascimbeni et al. (2018) & $\begin{array}{l}\text { NAFLD } \\
\text { Control }\end{array}$ & $\begin{array}{l}80 \\
69\end{array}$ & $\begin{array}{l}79.0 \\
77.0\end{array}$ & $\begin{array}{l}70.0(7.0) \\
73.0(8.2)\end{array}$ & $\begin{array}{l}28.0(3.8) \\
25.0(2.5)\end{array}$ & $\begin{array}{l}1.80(3.05) \\
1.40(1.87)\end{array}$ \\
\hline $\mathrm{R}^{2}(\%)$ & & & 15.95 & -10.90 & 41.60 & -13.12 \\
\hline$\beta$ & & & 0.297 & 0.995 & 1.058 & 0.041 \\
\hline$p$ value & & & 0.097 & 0.693 & 0.023 & 0.812 \\
\hline
\end{tabular}

Abbreviation: NA, not applicable.

controls (SMD $=-0.37,95 \% \mathrm{CI}:-0.84-0.09, p=0.116)$. In addition, heterogeneity in the pediatric/adolescent patients with ultrasound diagnosis was markedly lower $\left(I^{2}=7.4 \%\right.$, $p=0.356$ ) than the overall heterogeneity in the remaining pediatric/adolescent patients $\left(I^{2}=64.4 \%, p=0.024\right)$ (Figs. $2 \mathrm{~B}$ and $3 \mathrm{~B}$ ).

To further investigate the cause of heterogeneity in adult NAFLD patients, we performed univariate, random-effects meta-regression analysis to test whether the continuous variables, including sex distribution (percentage of males), mean age, BMI and HOMA-IR of NAFLD patients, could explain the high heterogeneity among studies. As the results show in Table 3 and Fig. 4, BMI was the significant influencing factor of the meta-analysis $\left(R^{2}=41.60, \beta=1.058\right.$, $p=0.023$, and the other tested variables did not show moderating effects.

\section{Sensitivity and publication bias analyses}

A leave-one-out sensitivity analysis was conducted to evaluate the stability of this meta-analysis (Fig. 5A). Each study included in our meta-analysis was evaluated one-by-one, to reflect the effect of pooled SMDs. The overall statistical significance did not change when any single study was omitted at one time. Therefore, the data presented in this metaanalysis is relatively stable and credible. Publication bias in this meta-analysis was confirmed by Egger's test, the results showed no significant publication bias $(p=0.152)$. In addition, no significant publication biases were observed in the adult population Egger's test $(p=0.275)$ and in the pediatric/adolescent population Egger's test $(p=0.450)$. Funnel plots of effect size $v s$. standard error were symmetrical $(p>0.05)$ (Fig. 5B).

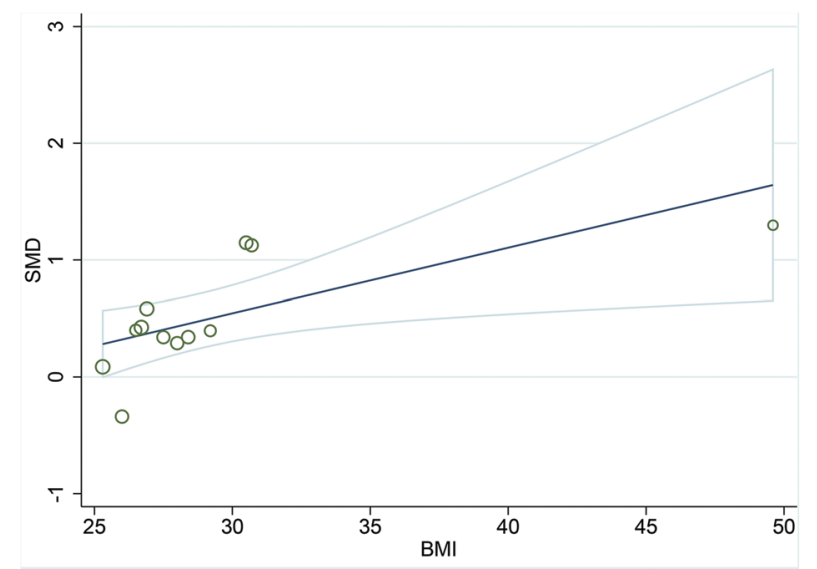

Fig. 4. Meta-regression analysis for the effect of BMI on the NAFLD patients and healthy controls. 
Liu S. et al: Circulating fetuin-A levels in NAFLD

A

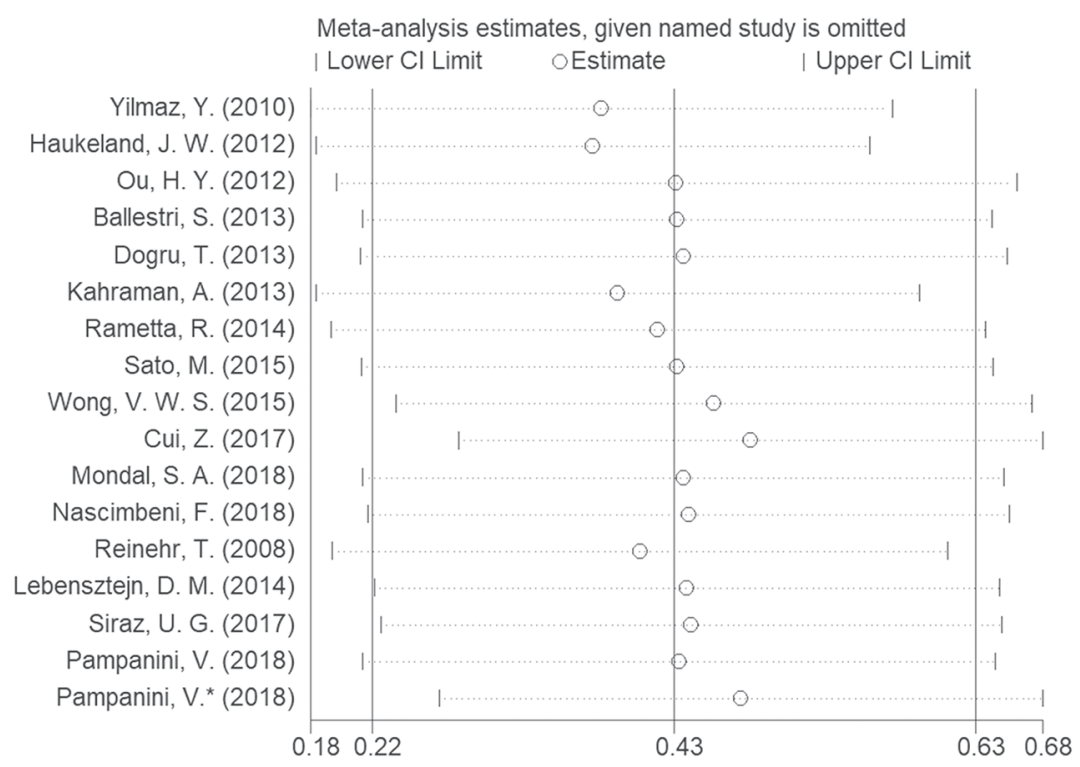

B

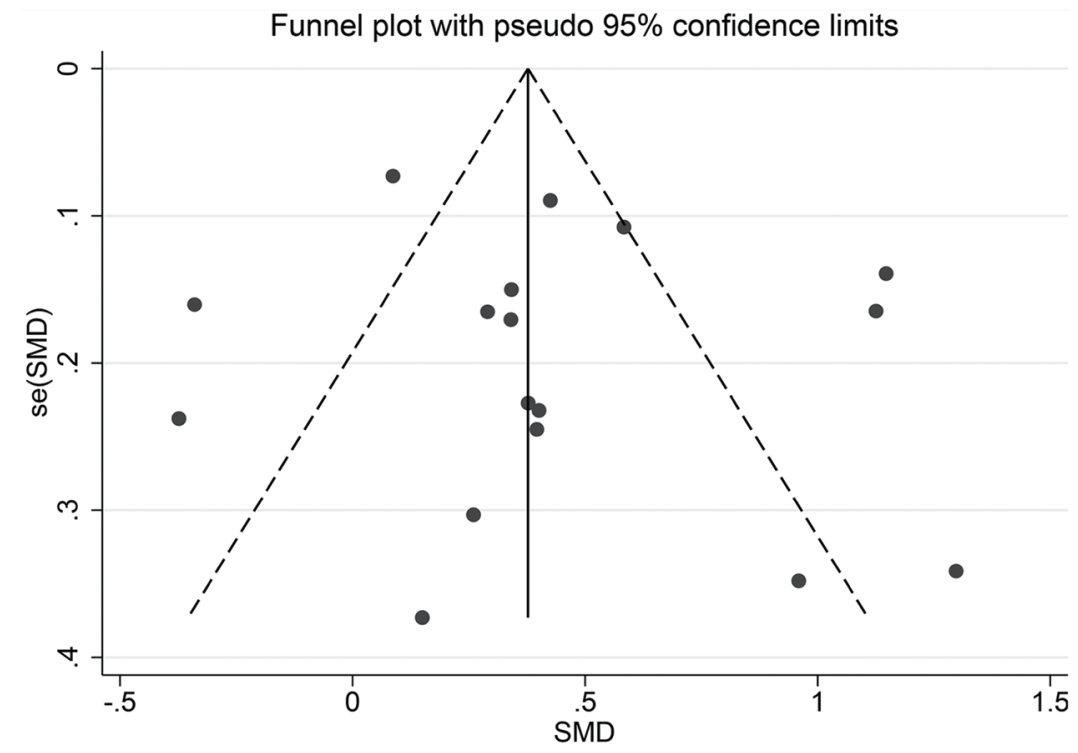

Fig. 5. Sensitivity analysis and forest plotting. (A) Sensitivity analysis of the summary odds ratio coefficients on the difference of circulating fetuin-A levels between NAFLD patients and healthy controls. (B) Forest plots on the difference of circulating fetuin-A levels between NAFLD patients and healthy controls.

\section{Effect of fetuin-A levels on grading of NAFLD}

In order to investigate whether circulating fetuin-A level can be used as a potential diagnostic biomarker for the classification of NAFLD, all the available information of circulating fetuin-A level on the classification of NAFLD were collected. As shown in Table 2, there were no significant differences of circulating fetuin-A level in the classification of NAFL vs. NASH in liver biopsy-proven NAFLD patients. In the liver biopsy-proven fibrosis patients, results from four studies suggested there was not association between circulating fetuin-A level and the development of fibrosis, two stud- ies showed that circulating fetuin-A levels were negatively correlated with fibrosis, and one study showed a positive correlation. In addition, one study found that circulating fetuin-A level was negatively correlated with serology-proven fibrosis, and another one study showed positive correlation in FibroScan-proven fibrosis (Table 2).

Discussion

NAFLD has become one of the most prevalent chronic liver diseases in the world and the major cause of liver-related 
Liu S. et al: Circulating fetuin-A levels in NAFLD

morbidity and mortality. ${ }^{1}$ Up to now, liver biopsy remains the recognized gold standard for the diagnosis of NAFLD. In consideration of the defects of biopsy, several imaging and serological diagnosis methods have been developed. Fetuin$A$ is a member of the fetuin group of serum binding proteins that are primarily synthesized by the hepatocytes. ${ }^{54}$ Some studies have investigated the circulating fetuin-A level between NAFLD patients and healthy controls in adult or pediatric/adolescent populations, but the results have been inconsistent. In this study, we conducted a meta-analysis to summarize the circulating fetuin-A levels in NAFLD patients and healthy controls, and a systematic review to determine the correlation of circulating fetuin-A level with the classification of NAFLD. As the results show, the circulating levels of fetuin-A in patients with NAFLD were significantly higher than in healthy controls for the included subjects. There was no difference of circulating fetuin-A level between NAFL and NASH patients. In addition, the relationship of circulating fetuin-A level with fibrosis remains unclear. Sensitivity analysis suggested that our meta-analysis was stable, and no significant publication bias was observed.

In this meta-analysis, the included studies were carried out from a different region in adult and pediatric/adolescent patients, and the diagnostic methods of NAFLD were also different. A marked heterogeneity was observed $\left(I^{2}=85.7\right.$, $p<0.001$ ) when the circulating fetuin-A levels were analyzed for the patients with NAFLD and healthy controls. In order to explore the potential factors which contribute to the heterogeneity, subgroup analysis based on the different variables was conducted. In the adults, circulating fetuinA level was significantly increased in patients with NAFLD compared to healthy controls, with a high heterogeneity $\left(I^{2}=88.8, p<0.001\right)$. Subsequently, the region of subjects and diagnostic methods of NAFLD were considered for analysis of the origin of heterogeneity. In the adults, circulating fetuin-A levels in Europeans were increased in patients with NAFLD but not in Eurasians and Asians, which suggested that region may be one of the influencing factors that contributes to the heterogeneity.

The circulating level of fetuin-A in patients with NAFLD did not vary according to the different diagnostic methods. Furthermore, meta-regression analysis suggested that BMI was the significant influencing factor to the heterogeneity. The reason why BMI contributes to the heterogeneity may be due to the incomplete correlation between BMI and the risk of NAFLD. Usually, subjects with metabolically healthy obesity, which is predominantly characterized by low liver fat content, may possess low risk of developing NAFLD, and the body fat distribution (more strongly than BMI) determines NAFLD in the general population; even patients with newly developed lipodystrophy can strongly develop NASH. ${ }^{55-57}$

The data of circulating fetuin-A level in NAFLD in pediatric/adolescent patients were relatively insufficient in that only four studies were included in this meta-analysis. We analyzed the pediatric/adolescent data using five individual studies, due to the study which was conducted by Pampanini et al. 27 that recruited two independent cohorts in which NAFLD was diagnosed with ultrasound and liver biopsy, respectively. There was no significance difference of circulating fetuin-A levels between patients with NAFLD and healthy controls. It is noteworthy that the high circulating fetuin-A level was observed in the ultrasound-diagnostic NAFLD in pediatric/adolescent patients. Notably, the heterogeneity of this subgroup analysis was very low $\left(I^{2}=7.4 \%\right.$, $p<0.001)$. The circulating fetuin-A levels in biopsy-proven NAFLD and healthy controls in pediatric/adolescent patients was tested for the first time and no obvious difference of circulating fetuin-A levels was found between the two groups. The different fetuin-A levels in ultrasound-diagnostic NAFLD compared to biopsy-proven NAFLD in pediatric/adolescent patients may due to the difference of diagnostic results of
NAFLD. In other words, some ultrasound-diagnostic NAFLD may belong to healthy controls when diagnosed by biopsy. In order to illuminate this query, more studies should be conducted to investigate the circulating fetuin-A level in liver biopsy-proven NAFLD in pediatric/adolescent patients.

Fetuin-A possesses a pro-inflammatory role and is downregulated during inflammation; expression of fetuin- $A$ is also inversely correlated with the level of C-reactive protein, which is a well-known marker of systemic inflammation. 33,47 Sato et $a l .{ }^{25}$ reported that fetuin-A might promote insulin resistance and inhibit NAFLD progression, but whether circulating fetuin-A level is positively or negatively correlated with the classification of NAFLD remains controversial. Our results have suggested that circulating fetuin-A level is not related with the classification of NAFL $v s$. NASH, as no significant change of fetuin-A level was found between the two groups. In consideration of the previous controversial results, more studies should be conducted to investigate the relationship of fetuin-A with the markers of inflammation. Besides, there was not a definite conclusion as to whether circulating fetuin-A level was associated with fibrosis due to the positive, negative, and unrelated correlations that have been reported. In order to clarify the significant role of circulating fetuin-A level on the diagnosis of fibrosis, more attention should be paid to the relationship of circulating fetuin-A level with fibrosis in different regions and ethnicity groups.

Our study had several limitations. First, considerable heterogeneity among studies limits the reliability of the results. Although we performed subgroup and meta-regression analyses to investigate some potential sources of heterogeneity, the high levels of heterogeneity cannot be reasonably explained in adult NAFLD. Second, due to the lack of detailed data on fetuin-A in the classification of NAFLD in some studies, we just reviewed the change of fetuin-A rather than making a quantitative analysis. Finally, all these studies are the cross-sectional or case-control epidemiological design, and the dynamic changes of circulating fetuin-A level in NAFL or NASH patients were unclear.

\section{Conclusions}

In summary, the circulating fetuin-A level was significantly higher in NAFLD patients than in healthy controls in adults and no difference was observed in pediatric/adolescent patients. BMI might be the risk factor that affects the stability of meta-analysis in adults. In pediatric/adolescent patients, ultrasound-proven NAFLD patients possess a markedly higher circulating fetuin-A level than healthy controls and there were no differences in biopsy-proven NAFLD patients. Our results suggest that circulating fetuin-A level could be regarded as a potential serum biomarker for the early diagnosis of NAFLD. Diagnostic values and differences of ultrasound and biopsy in pediatric/adolescent should be further studied to illuminate the significant effect of circulating fetuin-A level on pediatric/adolescent NAFLD. In addition, association of circulating fetuin-A level with fibrosis should be studied further.

\section{Funding}

This study was supported by grants from the National Natural Science Foundation of China (No. 31770837).

\section{Conflict of interest}

The authors have no conflict of interests related to this publication. 


\section{Author contributions}

Study concept and design (SL, YX), data collection ( $S \mathrm{~L}, \mathrm{JX}$ $\mathrm{ZZ}, \mathrm{MW}$, and $\mathrm{YW}$ ), analysis of data ( $\mathrm{SL}, \mathrm{JX}$, and $\mathrm{ZZ}$ ), drafting and writing of the manuscript ( $S L$ and $J X)$, revision of the manuscript $(Y X)$.

\section{References}

[1] Friedman SL, Neuschwander-Tetri BA, Rinella M, Sanyal AJ. Mechanisms of NAFLD development and therapeutic strategies. Nat Med 2018;24:908922. doi:10.1038/s41591-018-0104-9.

[2] Younossi ZM, Koenig AB, Abdelatif D, Fazel Y, Henry L, Wymer M. Global epidemiology of nonalcoholic fatty liver disease-Meta-analytic assessment of prevalence, incidence, and outcomes. Hepatology 2016;64:73-84. doi:10.1002/hep. 28431 .

[3] Starley BQ, Calcagno C], Harrison SA. Nonalcoholic fatty liver disease and hepatocellular carcinoma: a weighty connection. Hepatology 2010 51:1820-1832. doi:10.1002/hep.23594

[4] Hashimoto E, Taniai M, Tokushige K. Characteristics and diagnosis of NAFLD/ NASH. J Gastroenterol Hepatol 2013;28(Suppl 4):64-70. doi:10.1111/jgh. 12271.

[5] Kim CH, Younossi ZM. Nonalcoholic fatty liver disease: a manifestation of the metabolic syndrome. Cleve Clin J Med 2008;75:721-728. doi:10.3949/ ccjm.75.10.721.

[6] Stefan N, Häring HU, Cusi K. Non-alcoholic fatty liver disease: causes, diagnosis, cardiometabolic consequences, and treatment strategies. Lancet Diabetes Endocrinol 2019;7:313-324. doi:10.1016/S2213-8587(18)30154-2.

[7] Krishan S, Jain D, Bathina Y, Kale A, Saraf N, Saigal S, et al. Non-invasive quantification of hepatic steatosis in living, related liver donors using dual-echo Dixon imaging and single-voxel proton spectroscopy. Clin Radiol 2016;71:58-63. doi:10.1016/j.crad.2015.10.002

[8] Zhang Q, Zhang HM, Qi WQ, Zhang YG, Zhao P, Jiao J, et al. 3.0T ${ }^{1} \mathrm{H}$ magnetic resonance spectroscopy for assessment of steatosis in patients
with chronic hepatitis C. World J Gastroenterol 2015;21:6736-6744. with chronic hepatitis C. Wor
doi:10.3748/wjg.v21.i21.6736.

[9] Deng J, Fishbein MH, Rigsby CK, Zhang G, Schoeneman SE, Donaldson JS. Quantitative MRI for hepatic fat fraction and T2* measurement in pediatric patients with non-alcoholic fatty liver disease. Pediatr Radio 2014;44:1379-1387. doi:10.1007/s00247-014-3024-y.

[10] Keese D, Korkusuz $H$, Huebner F, Namgaladze D, Raschidi B, Vogl T]. In vivo and ex vivo measurements: noninvasive assessment of alcoholic fatty liver using $1 \mathrm{H}-\mathrm{MR}$ spectroscopy. Diagn Interv Radiol 2016;22:13-21. doi:10.5152/dir.2015.14331.

[11] de Lédinghen V, Vergniol J, Capdepont M, Chermak F, Hiriart JB, Cassinotto $C$, et al. Controlled attenuation parameter (CAP) for the diagnosis of steatosis: a prospective study of 5323 examinations. J Hepatol 2014;60:10261031. doi:10.1016/j.jhep.2013.12.018.

[12] Runge JH, Bakker PJ, Gaemers IC, Verheij J, Hakvoort TB, Ottenhoff R, et al. Measuring liver triglyceride content in mice: non-invasive magnetic resonance methods as an alternative to histopathology. MAGMA 2014; resonance methods as an alternative to histopa

[13] Chabanova E, Bille DS, Thisted E, Holm JC, Thomsen HS. ${ }^{1} \mathrm{H}$ MRS assessment of hepatic steatosis in overweight children and adolescents: comparison between 3T and open 1T MR-systems. Abdom Imaging 2013;38:315319. doi:10.1007/s00261-012-9930-2.

[14] Yki-Järvinen H. Diagnosis of non-alcoholic fatty liver disease (NAFLD). Diabetologia 2016;59:1104-1111. doi:10.1007/s00125-016-3944-1.

[15] Katsagoni CN, Georgoulis M, Papatheodoridis GV, Panagiotakos DB, Kontogianni MD. Effects of lifestyle interventions on clinical characteristics of patients with non-alcoholic fatty liver disease: A meta-analysis. Metabolism 2017;68:119-132. doi:10.1016/j.metabol.2016.12.006.

[16] Franzini M, Fornaciari I, Fierabracci V, Elawadi HA, Bolognesi V, Maltinti $S$, et al. Accuracy of $b-G G T$ fraction for the diagnosis of non-alcoholic fatty liver disease. Liver Int 2012;32:629-634. doi:10.1111/j.1478-3231. 2011.02673.x.

[17] Kosasih S, Zhi Qin W, Abdul Rani R, Abd Hamid N, Chai Soon N, Azhar Shah $\mathrm{S}$, et al. Relationship between serum cytokeratin-18, control attenuation parameter, NAFLD fibrosis score, and liver steatosis in nonalcoholic fatty liver disease. Int J Hepatol 2018;2018:9252536. doi:10.1155/2018/9252536.

[18] He L, Deng L, Zhang Q, Guo J, Zhou J, Song W, et al. Diagnostic value of CK-18, FGF-21, and related biomarker panel in nonalcoholic fatty liver disease: A systematic review and meta-analysis. Biomed Res Int 2017; 2017:9729107. doi:10.1155/2017/9729107.

[19] Jirak P, Stechemesser L, Moré E, Franzen M, Topf A, Mirna M, et al. Clinical implications of fetuin-A. Adv Clin Chem 2019;89:79-130. doi:10.1016/ bs.acc.2018.12.003.

[20] Mathews ST, Chellam N, Srinivas PR, Cintron V], Leon MA, Goustin AS, et al. Alpha2-HSG, a specific inhibitor of insulin receptor autophosphorylation, interacts with the insulin receptor. Mol Cell Endocrinol 2000;164:8798. doi:10.1016/s0303-7207(00)00237-9.

[21] Mathews ST, Singh GP, Ranalletta M, Cintron VJ, Qiang X, Goustin AS, et al. Improved insulin sensitivity and resistance to weight gain in mice null for the Ahsg gene. Diabetes 2002;51:2450-2458. doi:10.2337/diabetes.51.8.2450.

[22] Pal D, Dasgupta S, Kundu R, Maitra S, Das G, Mukhopadhyay S, et al.
Fetuin-A acts as an endogenous ligand of TLR4 to promote lipid-induced insulin resistance. Nat Med 2012;18:1279-1285. doi:10.1038/nm.2851.

[23] Stefan N, Häring HU. Circulating fetuin-A and free fatty acids interact to predict insulin resistance in humans. Nat Med 2013;19:394-395. doi: $10.1038 / \mathrm{nm} .3116$.

[24] Stefan N, Schick F, Häring HU. Ectopic fat in insulin resistance, dyslipidemia, and cardiometabolic disease. N Engl J Med 2014;371:2236-2237. doi:10.1056/NEJMc1412427.

[25] Sato M, Kamada $Y$, Takeda $Y$, Kida S, Ohara $Y$, Fujii $H$, et al. Fetuin-A negatively correlates with liver and vascular fibrosis in nonalcoholic fatty liver disease subjects. Liver Int 2015;35:925-935. doi:10.1111/liv.12478.

[26] Gerst F, Fritz AK, Lorza Gil E, Kaiser G, Wolf E, Haering HU, et al. Fetuin-A impairs islet differentiation and function via inhibition of TGFbeta-1 signalling. Diabetologia 2018;61:S205-S206.

[27] Pampanini V, Inzaghi E, Germani D, Alterio A, Puglianiello A, Alisi A, et al. Serum Fetuin-A levels in obese children with biopsy proven nonalcoholic fatty liver disease. Nutr Metab Cardiovasc Dis 2018;28:71-76. doi:10.1016/j.numecd.2017.09.008.

[28] Ballestri S, Meschiari E, Baldelli E, Musumeci FE, Romagnoli D, Trenti T, et al. Relationship of serum fetuin-A levels with coronary atherosclerotic burden and NAFLD in patients undergoing elective coronary angiography. Metab Syndr Relat Disord 2013;11:289-295. doi:10.1089/met.2012.0149.

[29] Weikert C, Stefan N, Schulze MB, Pischon T, Berger K, Joost HG, et al. Plasma fetuin-a levels and the risk of myocardial infarction and ischemic stroke. Circulation 2008;118:2555-2562. doi:10.1161/CIRCULATIONAHA.108.814418.

[30] Fisher $E$, Stefan $N$, Saar $K$, Drogan D, Schulze MB, Fritsche A, et al. Association of AHSG gene polymorphisms with fetuin-A plasma levels and cardiovascular diseases in the EPIC-Potsdam study. Circ Cardiovasc Genet cardiovascular diseases in the EPIC-Potsdam study. Circ Cardio

[31] Stefan N, Häring HU. The role of hepatokines in metabolism. Nat Rev Endocrinol 2013;9:144-152. doi:10.1038/nrendo.2012.258.

[32] Bourebaba L, Marycz K. Pathophysiological implication of Fetuin-A glycoprotein in the development of metabolic disorders: A concise review. J Clin Med 2019;8:2033. doi:10.3390/jcm8122033.

[33] Hennige AM, Staiger $H$, Wicke $C$, Machicao F, Fritsche A, Häring HU, et al. Fetuin-A induces cytokine expression and suppresses adiponectin produc-
tion. PLoS One 2008;3:e1765. doi:10.1371/journal.pone.0001765.

[34] Lanthier N, Lebrun V, Berghmans MP, Molendi-Coste O, Leclercq IA. Impact of kupffer cells on high fat induced insulin resistance and liver fetuin-A expression. J Hepatol 2015;62:S702. doi:10.1016/S0168-8278(15)31151-X.

[35] Liberati A, Altman DG, Tetzlaff J, Mulrow C, Gøtzsche PC, Ioannidis JP, et al. The PRISMA statement for reporting systematic reviews and metaanalyses of studies that evaluate health care interventions: explanation and elaboration. J Clin Epidemiol 2009;62:e1-e34. doi:10.1016/j.jclinepi.2009.06.006

[36] Zeng $X$, Zhang $Y$, Kwong JS, Zhang $C$, Li S, Sun F, et al. The methodological quality assessment tools for preclinical and clinical studies, systematic review and meta-analysis, and clinical practice guideline: a systematic review. J Evid Based Med 2015;8:2-10. doi:10.1111/jebm.12141.

[37] Liu CH, Ampuero J, Gil-Gómez A, Montero-Vallejo R, Rojas Á, MuñozHernández $\mathrm{R}$, et al. miRNAs in patients with non-alcoholic fatty liver disease: A systematic review and meta-analysis. J Hepatol 2018;69:13351348. doi:10.1016/j.jhep.2018.08.008.

[38] Hozo SP, Djulbegovic B, Hozo I. Estimating the mean and variance from the median, range, and the size of a sample. BMC Med Res Methodol 2005;5:13. doi:10.1186/1471-2288-5-13.

[39] Seo JA, Kim NH, Park SY, Kim HY, Ryu OH, Lee KW, et al. Serum retinol-binding protein 4 levels are elevated in non-alcoholic fatty liver disease. Clin Endocrinol (Oxf) 2008;68:555-560. doi:10.1111/j.13652265.2007.03072.x.

[40] Reinehr T, Roth CL. Fetuin-A and its relation to metabolic syndrome and fatty liver disease in obese children before and after weight loss. J Clin Endocrinol Metab 2008;93:4479-4485. doi:10.1210/jc.2008-1505.

[41] Yilmaz $Y$, Yonal O, Kurt R, Ari F, Oral AY, Celikel CA, et al. Serum fetuin A/a2HS-glycoprotein levels in patients with non-alcoholic fatty liver disease: relation with liver fibrosis. Ann Clin Biochem 2010;47:549-553. doi:10.1258/acb.2010.010169.

[42] Haukeland JW, Dahl TB, Yndestad A, Gladhaug IP, Løberg EM, Haaland T, et al. Fetuin $A$ in nonalcoholic fatty liver disease: in vivo and in vitro studies. Eur J Endocrinol 2012;166:503-510. doi:10.1530/EJE-11-0864.

[43] Ou HY, Yang YC, Wu HT, Wu JS, Lu FH, Chang CJ. Increased fetuin-A concentrations in impaired glucose tolerance with or without nonalcoholic fatty liver disease, but not impaired fasting glucose. J Clin Endocrinol Metab 2012;97:4717-4723. doi:10.1210/jc.2012-2414.

[44] Dogru T, Genc H, Tapan S, Aslan F, Ercin CN, Ors F, et al. Plasma fetuin$A$ is associated with endothelial dysfunction and subclinical atherosclerosis in subjects with nonalcoholic fatty liver disease. Clin Endocrinol (Oxf) 2013;78:712-717. doi:10.1111/j.1365-2265.2012.04460.x.

[45] Lebensztejn DM, Białokoz-Kalinowska I, Kłusek-Oksiuta M, Tarasów E, Wojtkowska M, Kaczmarski M. Serum fetuin A concentration is elevated in children with non-alcoholic fatty liver disease. Adv Med Sci 2014;59:8184. doi:10.1016/j.advms.2013.08.003.

[46] Rametta R, Ruscica M, Dongiovanni P, Macchi C, Fracanzani AL, Steffani $L$, et al. Hepatic steatosis and PNPLA3 I148M variant are associated with serum Fetuin-A independently of insulin resistance. Eur J Clin Invest 2014;44:627-633. doi:10.1111/eci.12280.

[47] Celebi G, Genc H, Gurel H, Sertoglu E, Kara M, Tapan S, et al. The relationship of circulating fetuin-a with liver histology and biomarkers of systemic inflammation in nondiabetic subjects with nonalcoholic fatty liver disease. Saudi J Gastroenterol 2015;21:139-145. doi:10.4103/1319-3767.157556. 
[48] Wong VW, Wong GL, Chan HY, Yeung DK, Chan RS, Chim AM, et al. Bacterial endotoxin and non-alcoholic fatty liver disease in the general population: a prospective cohort study. Aliment Pharmacol Ther 2015;42:731-740. doi:10.1111/apt.13327.

[49] Cui Z, Xuan R, Yang Y. Serum fetuin A level is associated with nonalcoholic fatty liver disease in Chinese population. Oncotarget 2017;8:107149107156. doi: 10.18632 /oncotarget. 22361.

[50] Şiraz ÜG, Doğan M, Hatipoğlu N, Muhtaroğlu S, Kurtoğlu S. Can fetuin-A be a marker for insulin resistance and poor glycemic control in children with type 1 diabetes mellitus? J Clin Res Pediatr Endocrinol 2017;9:293-299. type 1 diabetes mellitus?
doi: $10.4274 /$ jcrpe. 4532 .

[51] Nascimbeni F, Romagnoli D, Ballestri S, Baldelli E, Lugari S, Sirotti V, et al. Do nonalcoholic fatty liver disease and fetuin-A play different roles in symptomatic coronary artery disease and peripheral arterial disease? Diseases 2018;6:17. doi:10.3390/diseases6010017.

[52] Mondal SA, Dutta D, Kumar M, Singh P, Basu M, Selvan C, et al. Neck circumference to height ratio is a reliable predictor of liver stiffness and nonalcoholic fatty liver disease in prediabetes. Indian J Endocrinol Metab 2018;22:347-354. doi:10.4103/ijem.IJEM_31_18.

[53] Kahraman A, Sowa JP, Schlattjan M, Sydor S, Pronadl M, Wree A, et al. Fetuin-A mRNA expression is elevated in NASH compared with NAFL patients. Clin Sci (Lond) 2013;125:391-400. doi:10.1042/CS20120542.

[54] Meex RCR, Watt MJ. Hepatokines: linking nonalcoholic fatty liver disease and insulin resistance. Nat Rev Endocrinol 2017;13:509-520. doi:10.1038/ nrendo.2017.56.

[55] Stefan N, Häring HU, Schulze MB. Metabolically healthy obesity: the lowhanging fruit in obesity treatment? Lancet Diabetes Endocrinol 2018; 6:249-258. doi:10.1016/S2213-8587(17)30292-9.

[56] Stefan N. Causes, consequences, and treatment of metabolically unhealthy fat distribution. Lancet Diabetes Endocrinol 2020;8:616-627. doi:10.1016/ S2213-8587(20)30110-8.

[57] Eigentler T, Lomberg D, Machann J, Stefan N. Lipodystrophic nonalcoholic fatty liver disease induced by immune checkpoint blockade. Ann Intern Med 2020;172:836-837. doi:10.7326/L19-0635. 